\title{
EXPERIMENTAL STUDY OF BITUMINOUS MASTIC BEHAVIOUR USING DIFFERENT FILLERS BASED ON THE UCL METHOD
}

\author{
Diana Movilla-Quesada ${ }^{1}$, Ángel Vega-Zamanillo ${ }^{2}$, Miguel Ángel Calzada-Pérez $^{3}$, \\ Daniel Castro-Fresno ${ }^{4}$ \\ Department of Transports, Projects and Processes School of Engineering, University of Cantabria, \\ Santander 39005, Spain \\ E-mails: '1 diana.movilla@unican.es (corresponding author); ${ }^{2}$ angel.vega@unican.es; \\ ${ }^{3}$ calzadam@unican.es; ${ }^{4}$ daniel.castro@unican.es
}

Received 04 Feb. 2011; accepted 04 May 2011

\begin{abstract}
This research demonstrates that the use of suitable amounts of calcium hydroxide as an additive in asphalt mixtures can improve the aggregate-bitumen adhesion, forming a bituminous mixture which is more resistant to traffic loads and the action of water.

The analysis was performed using the UCL method and the Cantabrian Test, taking as a case study three types of filler with different natures, mixed with $4.5 \%$ bitumen. The results are presented as state curves, which show clear differences between the three fillers, demonstrating that the hydroxide suffers small wear losses in concentrations close to $1.3 \%$, indicating a significant reduction in the risk of plastic deformation, and an improvement in the mixture durability and/or adhesiveness.
\end{abstract}

Keywords: bituminous mixture, filler, bitumen, UCL method, state curves.

Reference to this paper should be made as follows: Movilla-Quesada, D.; Vega-Zamanillo, Á.; Calzada-Pérez, M. Á.; Castro-Fresno, D. 2013. Experimental study of bituminous mastic behaviour using different fillers based on the UCL method, Journal of Civil Engineering and Management 19(2): 149-157.

\section{Introduction}

Many of the defects found in roads are related to the fragility of pavements which deteriorate over time due to external conditions or the poor properties of the materials used. The purpose of this research is to develop a bituminous mixture, which is immediately applicable in top coats, improving its resistance and properties by analyzing the aggregate-bitumen adhesion.

The use of calcium hydroxide for the preparation of bituminous mixtures in Europe is uncommon compared with the U.S.A. Some countries such as the Netherlands, Austria and Germany (Kunesch et al. 2007) have roads with bituminous mixtures prepared with calcium hydroxide in their composition and they show good mechanical properties and successful results throughout their life cycles (Hicks et al. 2003). However, in Spain the use of calcium hydroxide is restricted to Formula 1 circuits such as Valencia or Alcañiz, but has not yet been used on highways, in which cement is preferred (Molenaar et al. 2010).

In 2007 the Polytechnic University of Catalonia in partnership with the University of La Plata (Argentina) presented a series of results related to a functional method called "Universal Caracterización de Ligantes" (Universal Binder Characterization) better known as the UCL method, in which they showed that if the filler volume ratio did not exceed $\mathrm{Cv} / \mathrm{Cc}$, there would be a good aging resistance (Lee et al. 2008).

The development of this method has led to a variation in the kinds of filler used (Miró-Recasens et al. 2005). An experimental study carried out by the University of Catalonia used of crumbed rubber as a filler in asphalt mixtures and the results showed that this type of filler decreases the compactness of the mixture and were responsible for producing greater losses in the Cantabrian test.

Calcium hydroxide reduces the risk of plastic deformations, thus improving the aggregate/bitumen adhesion resistance due to the water effect. However, not only will calcium hydroxide be used to perform these tests, but it will also be compared with cement and calcium carbonate, the most common materials used in highway applications (Bocci et al. 2011).

\section{Materials and methods}

\subsection{Filler characterization}

The characterization tests were performed in the Airports and Roads Laboratory in the University of Cantabria, using the UCL method to study the 
behavior of the different fillers in the bituminous mastics. Both intrinsic and extrinsic properties of fillers in the mastic were determined.

The fillers used were as follows: Calcium hydroxide $\mathrm{CL} 90(\mathrm{CaO}+\mathrm{MgO} \geq 90)$, quarried calcium carbonate and CEM II/A-L 32.5R (Limestone Portland cement and $32.5 \mathrm{MPa}$ of compression resistance) in accordance with the EN 197-1 (2000) standard.

The apparent density and specific mass was found by the toluene test, according to the standard NLT 176 (1992). The degree of filler activity was related to its fineness from the viewpoint of binder stabilization in the filler-bitumen system. Therefore, the apparent density values of the three fillers should be in a range of values between 0.5 and $0.8 \mathrm{~g} / \mathrm{cm}^{3}$, as correspond to an average activity suitable for use in asphalt mixtures. In this case, the calcium hydroxide and calcium carbonate were outside the range as they have a lower specific mass than the cement and greater fineness, which leads to their hydrophilic character. However, as they are artificial mineral fillers, these results do not cause any problem in their characterization. The specific mass of each filler was calculated according to the Argentinian standard IRAM 1542 (1992) (Páez-Dueñas et al. 2009).

\subsection{Bituminous mixtures}

Bituminous mixtures have an AC $16 \mathrm{~S}$ grain-size distribution with ophitic aggregate and a void percentage that depends on the filler used. According to the standard, the void volume for top coats must be between 4 and $6 \%$. However, it should be noted that the manufacture of the Marshall sample for the Cantabrian test was less strict as it was compacted using 50 strikes for each face, which implies an increase of voids. $4.5 \%$ B 60/70 (60-70 Range of penetration bitumen at $25^{\circ} \mathrm{C}$ ) bitumen was used for mixing, which is characterized by the properties listed in Table 1 .

The worst-case of in-situ compaction was chosen for experimentally comparing similar compacted samples.

\subsection{UCL Method}

The UCL method analyzes the behavior of bitumen and filler in the mixture using the attrition results obtained by the Cantabrian test, indirectly evaluating

Table 1. Specific properties of bitumen

\begin{tabular}{llr}
\hline Test & Standard & Results \\
\hline Penetration 25C [0.1 mm] & NTL 124 & 65.0 \\
Softening point (C) & NTL 125 & 49.9 \\
Fraas breaking point test (C) & NTL 182 & -16.0 \\
Penetration index & NTL 181 & -0.6 \\
\hline
\end{tabular}

other properties such as adhesion, thermal susceptibility and aging.

When making the mixture of bitumen and filler, an increase was produced in binder power and viscosity, but not always the best possible way (Radziszewski 2007). Many studies performed to today only take into account the size and plasticity of the filler using filler/ bitumen mass ratios, which are determined without taking into account other properties such as density, porosity or nature (Valdés et al. 2011).

\subsubsection{Dry and water immersion adhesion}

The aim of this test is to study the resistance of the mixture to the action of water. This parameter depends on the cohesion and the wrapped to produce the bitumen on the aggregate, as the water, its properties, is able to separate the compounds and decrease the cohesion of the mixing.

The nature of the filler is one of the most important properties when carrying out any analysis of the effect produced in the bituminous mastics. The chemical activity that occurs through contact between the filler and the water is very important in the subsequent behavior of the colloidal system. Therefore, the plastic nature of fillers more related to water bitumen tends to produce poor conditions in the mix, since having an affinity for water will separate from the binder and result unwrapped phenomenon resulting in disintegration of the material, and therefore a life cycle too short of placing.

The nature of the filler is one of the most important properties in any analysis of the effect produced in the bituminous mastics. The chemical activity that occurs through contact between filler and water is very important in the subsequent behavior of colloidal system. Therefore the fillers of plastic nature more related to water comparing with the bitumen, tend to produce poor conditions in the mix, since having an affinity for water will separate from the binder and result unwrapped phenomenon that will lead to disintegrations the material, and therefore a short life cycle (Muniandy et al. 2009).

The material losses were calculated using the Cantabrian test, having different volume ratio and therefore different amounts of filler in each one. The increase in these losses is directly related to the nature, porosity and density of the fillers.

\subsubsection{Effect of aging temperature}

The UCL method enables the analysis of the aging and wear resistance of mixtures and disintegration, as the bitumen loses properties due to the effect of time and temperature. In this test, the samples were tested at a temperature of $163{ }^{\circ} \mathrm{C}$ during time intervals of 0 , $5,20,40$ and 72 hours with different amounts of filler, before the attrition loss test (Devecseri 2010). 
Table 2. Results obtained from the different samples

\begin{tabular}{|c|c|c|c|c|c|c|c|c|c|}
\hline & \multirow[b]{2}{*}{$\begin{array}{l}\text { Unit } \\
\text { weight } \\
\left(\mathrm{g} / \mathrm{cm}^{3}\right)\end{array}$} & \multirow[b]{2}{*}{$\begin{array}{l}\text { Critical } \\
\text { concentration }\end{array}$} & \multirow[b]{2}{*}{$\mathrm{Cv} / \mathrm{Cc}$} & \multicolumn{3}{|c|}{ Apparent density } & \multicolumn{3}{|c|}{ Voids } \\
\hline & & & & $\begin{array}{l}\text { Average } \\
\text { value } \\
\left(\mathrm{g} / \mathrm{cm}^{3}\right)\end{array}$ & $\begin{array}{l}\text { Standard } \\
\text { deviation } \\
\left(\mathrm{g} / \mathrm{cm}^{3}\right)\end{array}$ & $\begin{array}{l}\text { Variation } \\
\text { coefficient } \\
(\%)\end{array}$ & $\begin{array}{l}\text { Average } \\
\text { value }(\%)\end{array}$ & $\begin{array}{l}\text { Standard } \\
\text { deviation } \\
(\%)\end{array}$ & $\begin{array}{l}\text { Variation } \\
\text { coefficient } \\
(\%)\end{array}$ \\
\hline \multirow{5}{*}{ 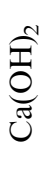 } & \multirow{5}{*}{2.35} & \multirow[t]{5}{*}{0.14} & 0.5 & 2.305 & 0.007 & 0.29 & 8.593 & 0.248 & 0.0289 \\
\hline & & & 1 & 2.318 & 0.011 & 0.47 & 7.583 & 0.426 & 0.0562 \\
\hline & & & 1.5 & 2.319 & 0.014 & 0.60 & 7.195 & 0.601 & 0.0835 \\
\hline & & & 2 & 2.334 & 0.020 & 0.86 & 8.418 & 0.344 & 0.0408 \\
\hline & & & 2.5 & 2.273 & 0.019 & 0.84 & 8.632 & 0.280 & 0.0324 \\
\hline \multirow{5}{*}{$\begin{array}{l}\overrightarrow{0} \\
\stackrel{\Xi}{0} \\
\stackrel{0}{0}\end{array}$} & \multirow{5}{*}{3.00} & \multirow[t]{5}{*}{0.31} & 0.25 & 2.317 & 0.010 & 0.45 & 8.700 & 0.204 & 0.0235 \\
\hline & & & 0.5 & 2.330 & 0.020 & 0.86 & 7.732 & 0.260 & 0.0336 \\
\hline & & & 0.75 & 2.350 & 0.011 & 0.47 & 8.677 & 0.259 & 0.0299 \\
\hline & & & 1 & 2.355 & 0.020 & 0.87 & 7.350 & 0.336 & 0.0457 \\
\hline & & & 1.1 & 2.383 & 0.023 & 0.94 & 6.662 & 0.321 & 0.0482 \\
\hline \multirow{5}{*}{ 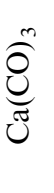 } & \multirow{5}{*}{2.80} & \multirow[t]{5}{*}{0.28} & 0.25 & 2.301 & 0.012 & 0.52 & 8.700 & 0.223 & 0.0256 \\
\hline & & & 0.5 & 2.315 & 0.014 & 0.60 & 7.732 & 0.220 & 0.0284 \\
\hline & & & 0.75 & 2.346 & 0.008 & 0.35 & 6.843 & 0.289 & 0.0423 \\
\hline & & & 1 & 2.373 & 0.008 & 0.33 & 8.350 & 0.296 & 0.0355 \\
\hline & & & 1.2 & 2.377 & 0.018 & 0.76 & 6.662 & 0.139 & 0.0209 \\
\hline
\end{tabular}

\subsubsection{Thermal susceptibility}

The viscosity is an important parameter to consider in construction work, as the pavement will be located in areas with a certain variation in temperature (Chen et al. 2011).

Therefore, the Cantabrian test was carried out according to the thermal susceptibility of the mixture, using temperatures ranging from below the point of fragility of bitumen to values above its softening point ( -16 and $49.9{ }^{\circ} \mathrm{C}$ respectively). The following temperatures were used: $-29,-3,10,20,40$ and $60{ }^{\circ} \mathrm{C}$.

\subsubsection{Volume concentrations}

The different volume concentrations of each filler were determined from the percentage of bitumen used in the aggregate. According to the technical specifications, the maximum ratio by weight of the $\mathrm{AC} 16 \mathrm{~S}$ filler-bitumen mixture must correspond to $7 \%$ (approximately $54 \mathrm{~g}$ ), thus determining the maximum volume ratio for each filler.

\subsubsection{Critical concentration}

After obtaining the results of the specific weights of each filler, the test was performed to obtain the different critical concentrations.

To calculate the relation between the filler incorporated volume and the optimal filler volume, it is necessary to calculate the critical concentration of each one (Vikan et al. 2007). The critical concentration is the ratio between the actual volume of filler and its apparent volume in a bituminous mixture above which it begins to lose its viscous character IRAM 1542 (1992):

$$
C_{c}=\frac{P_{f}}{V_{a} \cdot \gamma},
$$

where: $C_{c}$ - critical concentration; $P_{f}$ - weight of the filler (gr.); $V_{a}$ - apparent volume of the filler obtained from kerosene sedimentation test in 24 hours; $\gamma$ - unit weight of filler $\left(\mathrm{g} / \mathrm{cm}^{3}\right)$.

Table 3. Losses produced in adhesiveness test when dry and after water immersion

\begin{tabular}{|c|c|c|c|}
\hline & $\mathrm{Cv} / \mathrm{Cc}$ & Dry losses (\%) & $\begin{array}{c}\text { Water immersion } \\
\text { losses }(\%)\end{array}$ \\
\hline \multirow{5}{*}{ 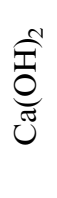 } & 0.5 & 8.8 & 44.6 \\
\hline & 1.0 & 14.8 & 53.6 \\
\hline & 1.5 & 11.0 & 18.2 \\
\hline & 2.0 & 19.7 & 27.1 \\
\hline & 2.5 & 45.1 & 47.6 \\
\hline \multirow{5}{*}{ 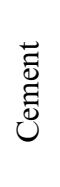 } & 0.3 & 10.5 & 30.9 \\
\hline & 0.5 & 8.1 & 9.0 \\
\hline & 0.8 & 7.6 & 8.1 \\
\hline & 1.0 & 14.3 & 5.6 \\
\hline & 1.1 & 1.1 & 2.9 \\
\hline \multirow{5}{*}{$\overbrace{\tilde{U}}^{\infty}$} & 0.3 & 11.9 & 47.3 \\
\hline & 0.5 & 13.2 & 23.1 \\
\hline & 0.8 & 9.7 & 6.8 \\
\hline & 1.0 & 9.6 & 12.1 \\
\hline & 1.2 & 6.7 & 8.0 \\
\hline
\end{tabular}


152 D. Movilla-Quesada et al. Experimental study of bituminous mastic behaviour using different fillers based on the UCL...
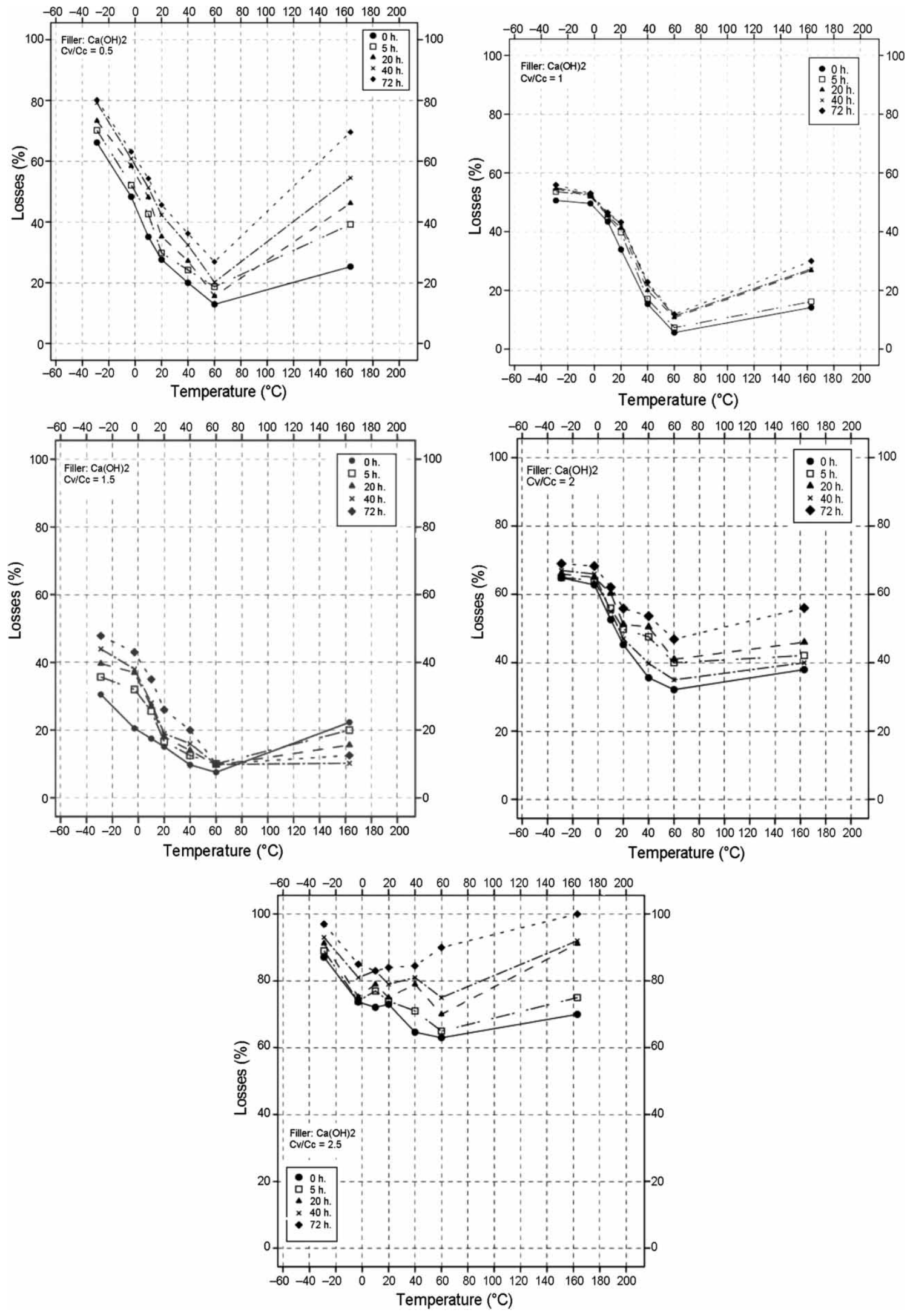

Fig. 1. State curves of mixtures with calcium hydroxide as filler 

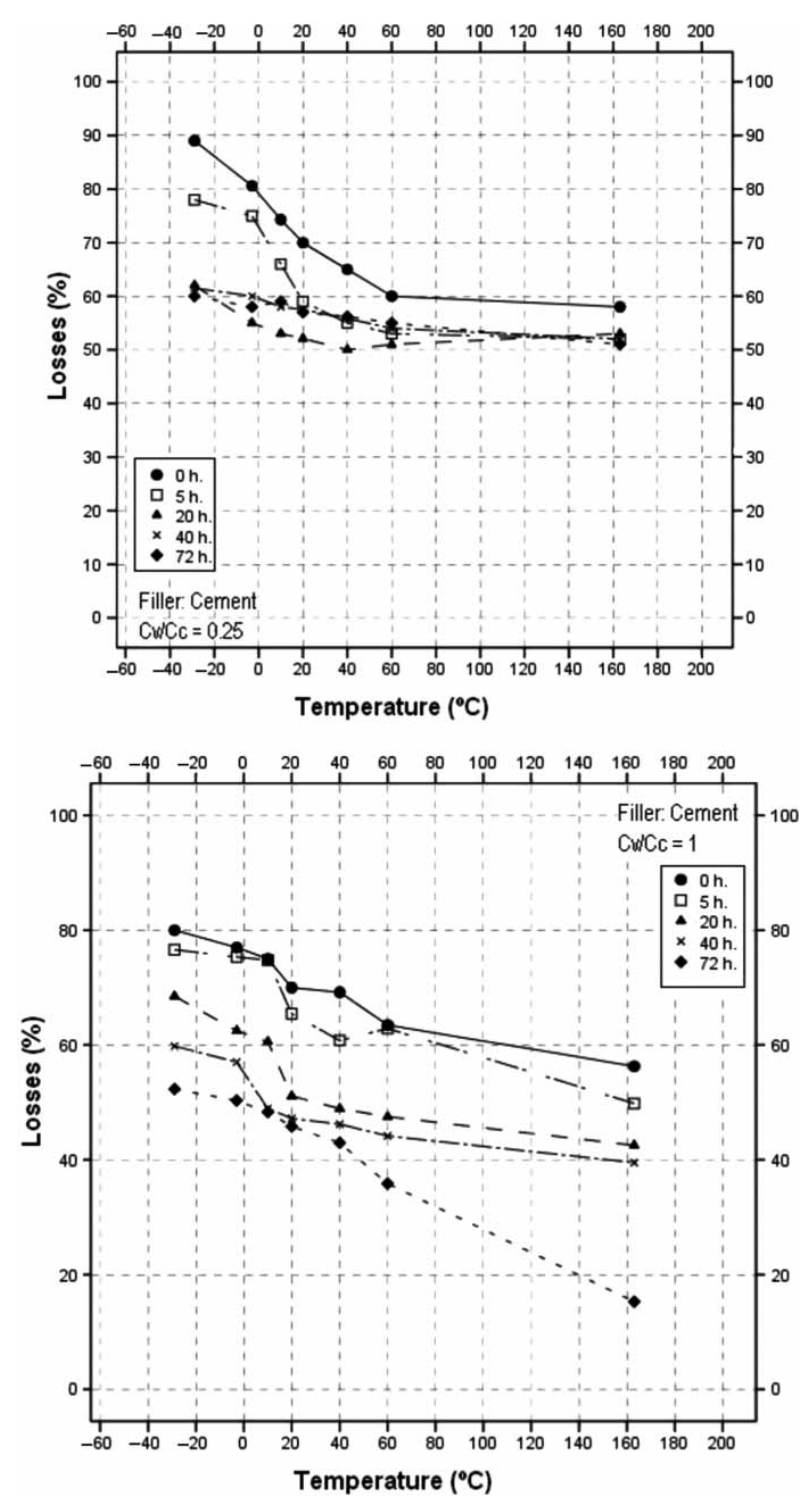

Fig. 2. Losses/temperature produced in samples with cement

\subsubsection{State curves}

The state curves are tools used to analyze the results obtained from the UCL method, showing the evolution of losses obtained from the Cantabrian test for each time interval at a specific temperature. Using these curves, the variations produced in the slope of the curve were analyzed as the aging of filler and bitumen takes place.

\section{Results and discussion}

The manufacturing process in the laboratory was performed evenly, producing a series of three samples for each type of concentration and filler.

Table 2 shows the average value, standard deviation and apparent density and void percentage varia-

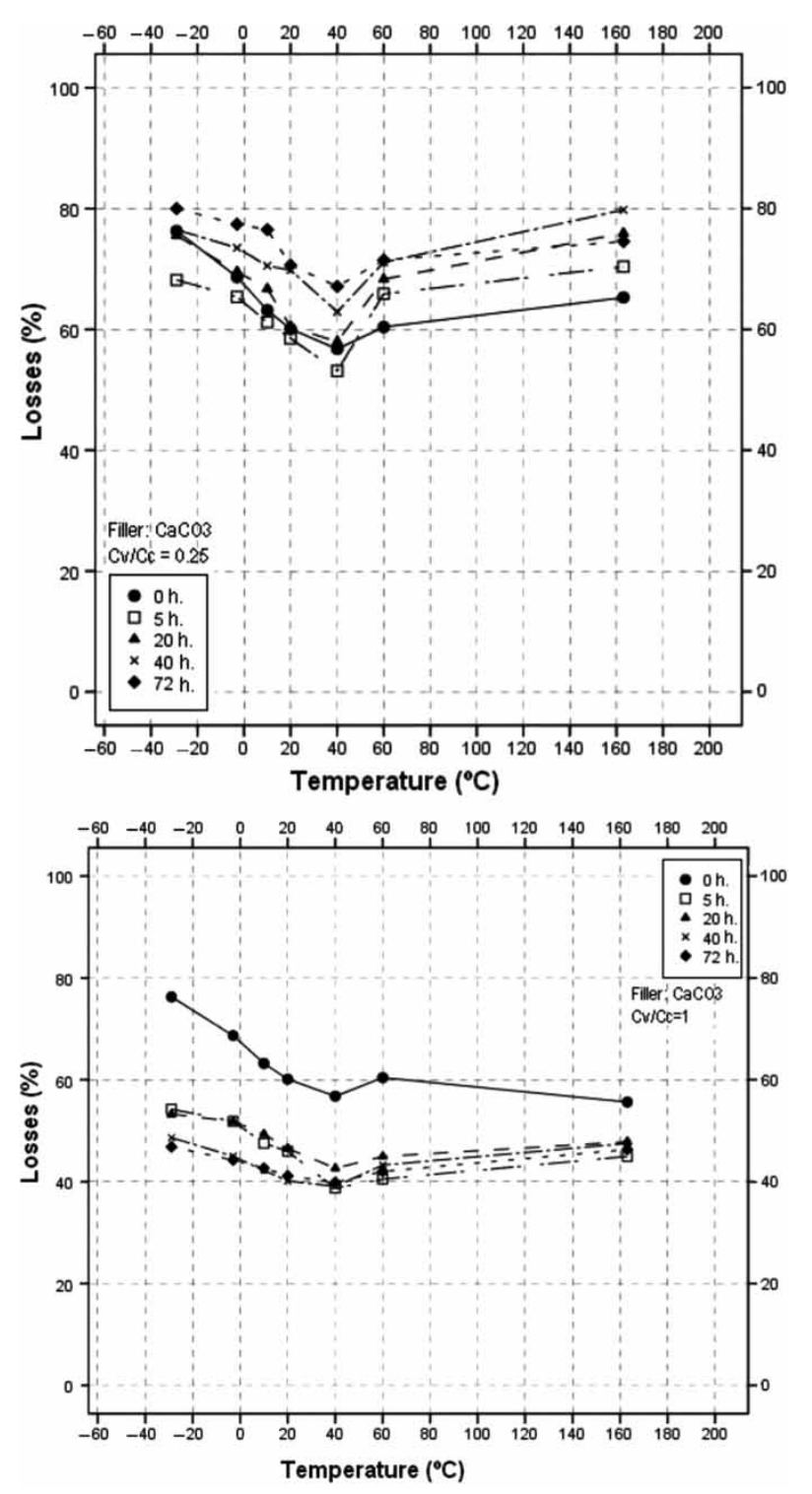

Fig. 3. State curves for mixtures made with calcium carbonate as filler

tion coefficient for each of the series of the three types of filler used.

The study sample deviation of the mixture containing calcium hydroxide, to study the apparent density and voids was less than $0.86 \%$ and $8.35 \%$ respectively to the mean value obtained. However, for mixtures of cement and calcium carbonate the values were no greater than $0.94-4.82 \%$ and $0.76-4.23 \%$, respectively.

\subsection{Adhesiveness when dry and after water immersion}

A series of three samples was made for each volume ratio, testing them using the Cantabrian test at $300 \mathrm{rpm}$ and a temperature of $25{ }^{\circ} \mathrm{C}$. Once the dry adhesiveness tests were performed to immersion in water. 


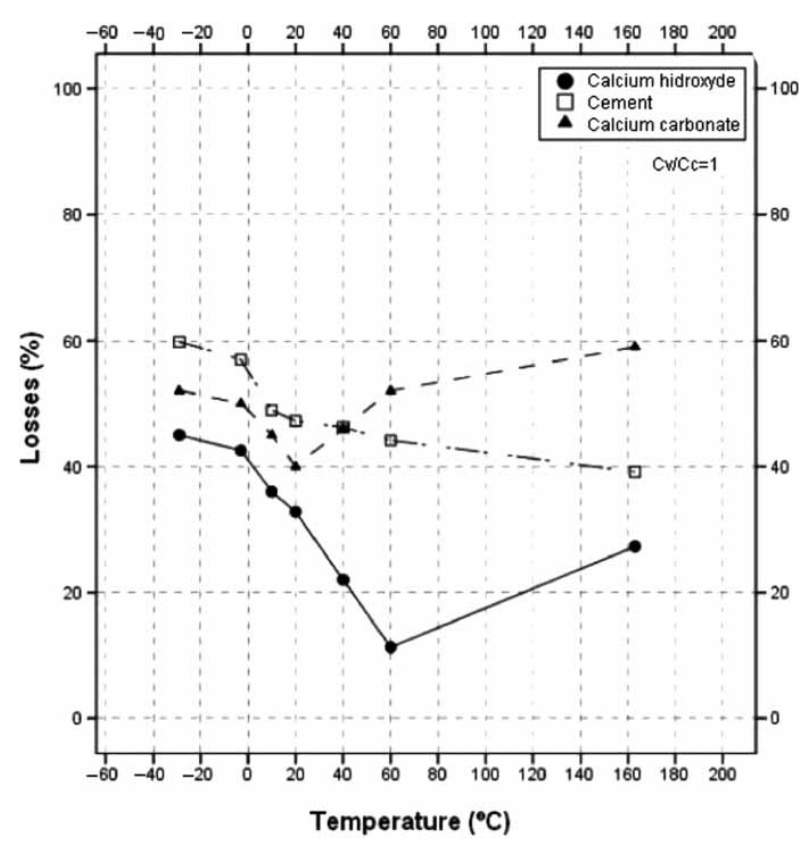

Fig. 4. Losses produced for each filler in a period of 40 hours

The three samples of each volume ratio were submerged in a water bath at a temperature of $60{ }^{\circ} \mathrm{C}$ for 24 hours. After this time, the samples were left for 24 hours at $25^{\circ} \mathrm{C}$ to be tested later.

Table 3 shows the results obtained in tests when dry and after water immersion tests.

The maximum value of loss is below $50 \%$ in submerged mixtures indicating that the use of calcium hydroxide as filler does not reduce the mixture's adhesiveness. Calcium hydroxide is an alkaline material and therefore combines well with the acidic bitumen and aggregate. After water immersion was showed a tendency of the adhesiveness to increase when the filler content was higher. The bitumen contains catalysts which are captured by calcium hydroxide in the oxidation process. The polar molecular generated during aging are the cause of the stiffening of the mastic, but being captured by the hydroxide are completely void.

Once the basic reaction with water was produced, excess lime did not provide any positive effect on the adhesiveness, but the excess filler occupies the voids an extreme may be formed ruts, hence the losses are highest for maximum values of filler, with no internal friction of gross particles.

In the case of cement, the higher the filler content in the dry lower losses occur. The mastic saturation value is very close to the maximum filler/bitumen ratio allowed by the Spanish Highways Agency (2007) for binder because of their behavior; the best adhesiveness is obtained with a high saturation level. The behavior of the cement after water immersion is totally contrary to the lime behavior in the produced losses. This is because, when more cement is added, it reacts positively with the water creating a suitable binder for the adhesiveness is high and both the values of losses are small relative filler/bitumen high.

The Calcium carbonate maintained the loss in a low range and the curves roughly present pending. The chemical reactions with bitumen are responsible for the good adhesiveness of the mixture. In contrast, the results after water immersion were not satisfactory, since the water adversely affects the bond between the filler and bitumen.

\subsection{State curves. Effect of aging and the type of filler on thermal susceptibility}

The state curves demonstrate the cohesive properties of the mixture from the analysis of the thermal susceptibility of bitumen exposed to temperatures of $-29,-3,10,20,40$ and $60{ }^{\circ} \mathrm{C}$ over different times.

Once the test is developed state were performed the state curves which represent the losses that occur for each range of temperature and aging. It was analyzed in this way, the thermal susceptibility of aging from occurring in the bitumen and filler.

Fig. 1 shows the state curves for different concentrations of calcium hydroxide as filler. The maximum temperature used was $163{ }^{\circ} \mathrm{C}$, the same for all concentrations. At higher concentrations of calcium hydroxide the losses were below $50 \%$ to reach the "overfilling", in this moment the losses increase for all the temperatures to reach losses of $100 \%$ for $\mathrm{Cv} / \mathrm{Cc}$ of 2.5 .

The mixes with cement had different behaviour. A test was performed for concentrations of $0.25,0.5$, $0.75,1$ and 1.1 .

Fig. 2 shows that more content of cement and more temperature minor losses produced in the mixtures. However, when the samples were tested at low temperatures for a period of 72 hours, an increase was produced in their degradation.

The mixtures made with calcium carbonate as filler reached higher than the previous losses. There was a significant increase in losses when the temperature was lowered, while at higher temperatures and for longer times, the losses remained more or less constant. Comparing with mixtures made with calcium hydroxide was saved some relation, although the same concentration is much greater the weight of calcium carbonate than the lime.

Fig. 3 shows the losses produced for $\mathrm{Cv} / \mathrm{Cc}$ of 0.25 and 1 of calcium carbonate as filler.

Fig. 4 shows the differences in behaviour for each filler for a $\mathrm{Cv} / \mathrm{Cc}$ of 1 at different temperatures during a period of 40 hours using the same bitumen.

At high temperatures, the calcium hydroxide shows better behavior than the cement and calcium carbonate, but the losses tend to increase when it exceeds $160{ }^{\circ} \mathrm{C}$, at which time the mastic begins to stiffen and therefore causes a greater loss of material. 

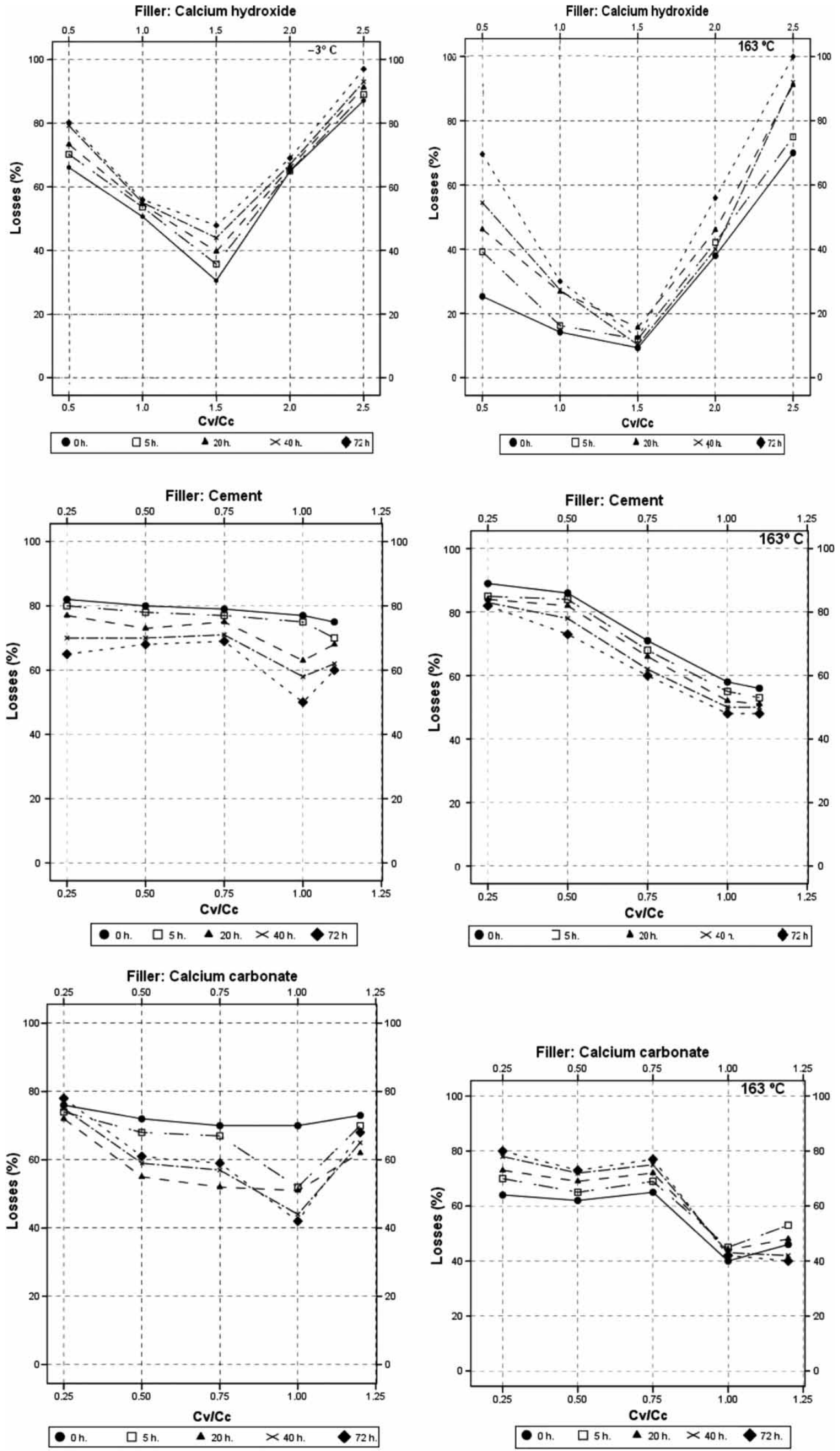

Fig. 5. Losses produced at -3 and $163{ }^{\circ} \mathrm{C}$ for each fille 


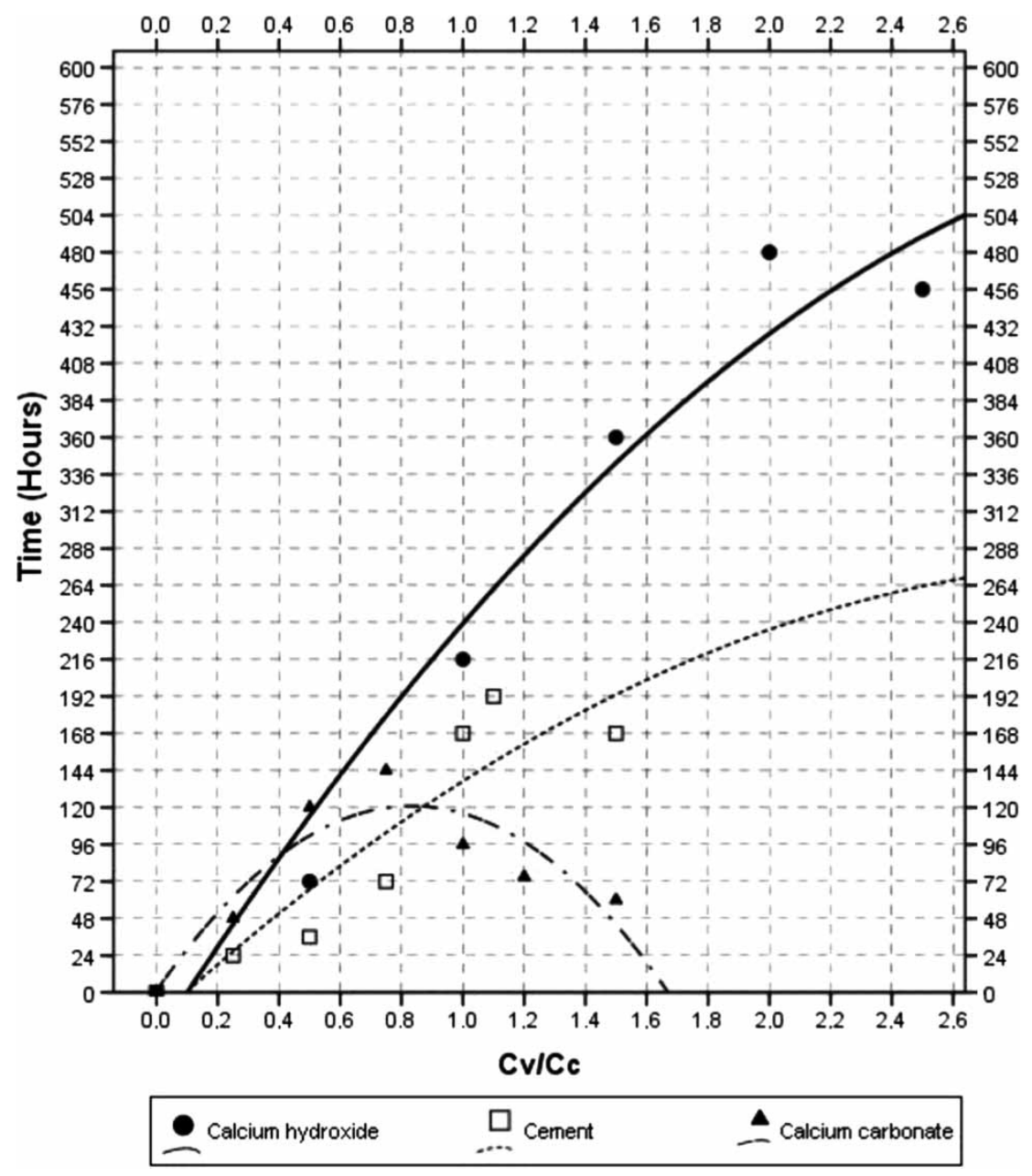

Fig. 6. Determination of the optimal filler content, analyzing the time to obtain $45 \%$ losses

\subsection{Optimal filler content determination}

Fig. 5 shows the influence of the volumetric ratio for each temperature, taking into account the losses produced by the Cantabrian test. For a temperature of $-3{ }^{\circ} \mathrm{C}$ the optimal value was for $\mathrm{Cv} / \mathrm{Cc}$ of 1.5 leading to increased losses afterwards due to the "overfilling".

For a temperature of $163{ }^{\circ} \mathrm{C}$, the values of losses reached are also given for the case of 1.5 , rising to losses of $100 \%$ for concentrations of 2.5 .

Fig. 6 shows an analysis of the time that was necessary to obtain the same losses as if they were tested without filler and temperature influence. From the maximum values obtained in each curve, the volume concentration responsible for a greater resistance to aging can be determined.

\section{Conclusions}

The study carried out on the behavior of asphalt mixtures with different content of filler was performed from the Universal Method of Binder Characterization (UCL). Through this investigation have been conducted different tests that allowed analyzing the adhesiveness, attrition and aging under the influence of different factors.

This is simplified tests in which Marshall samples are tested at Cantabrian test producing mass loss which can obtain indirectly the parameters of interest for this research.

The behavior of calcium hydroxide as filler for mixtures of $16 \mathrm{~S}$ AC type is affected by temperature and time. The best values of thermal susceptibility and aging are given for $\mathrm{Cv} / \mathrm{Cc}$ close to 1 and 1.5 , as the losses are less than $50 \%$. For higher $\mathrm{Cv} / \mathrm{Cc}$ concentrations, the losses increase, which indicates that "overfilling" of the mastic is produced, which can be harmful as it begins to cause stiffening of the bituminous mastic.

However, if the adhesiveness parameter is analyzed for roads located in dry places, calcium hydroxide may be applicable, but in other places with a level of moisture and rainfall, another type of testing would be required as water sensitivity as to provide greater security for your application.

Otherwise, analyzing the different fillers versus time and temperature, with a concentration very close to each one of them, calcium hydroxide is more 
durable than compared to higher temperatures, which indicates that if used in a suitable proportion may be very profitable when using it at work.

\section{Acknowledgments}

This work was financed by the Spanish Ministry for the Environment. Research project NATURPAV. The authors would like to express their gratitude to Calcinor Ltd and the Construction Technology Research Group (GITECO) at the University of Cantabria.

\section{References}

Bocci, M.; Grilli, A.; Cardone, F.; Graziani, A. 2011. A study on the mechanical behaviour of cement-bitumen treated materials, Construction and Building Materials 25(2): 773-778.

http://dx.doi.org/10.1016/j.conbuildmat.2010.07.007

Chen, J.; Zhou, L.; Yan, Z. 2011. Hydrated lime content in asphalt mastic based on high temperature performances, Applied Mechanics and Materials 40-41: 669-674.

Devecseri, G. 2010. Effect of heating on the physical properties of asphalt aggregates, Periodica Polytechnica: Civil Engineering 54(1): 53-60. http://dx.doi.org/10.3311/pp.ci.2010-1.06

EN 197-1 Cement. Composition, specifications and conformity criteria for common cements. 2000. European committee for standardization. Brussels. 30p.

Hicks, R. G.; Todd, P. E.; Scholz, V. 2003. Life cycle costs for lime in hot Mix Asphalt. Prepared for National Lime Association, USA. Vol. 2. 156 p.

Highways Agency General technical requirements specification for road and bridge works (PG-3). Article 542: hot mix asphalt concrete or bituminous. 2007. Ministry for Development, Spain. 240 p.

IRAM 1542 Fillers for asphalt mixtures. Determination of the critical ratio and density. 1992. Argentinean committee for standardization. $15 \mathrm{p}$.

Kunesch, C. 2007. Asphaltmodifizierung mit Kalkhydrat. Ergebnisseaus aus Praxis [Asphalt modification with hydrated lime. Results from practice], Gestrata Journal 111: 7-12.
Lee, S.-J.; Amirkhanian, S. N.; Shatanawi, K.; Thodesen, C. 2008. Influence of compaction temperature on rubberized asphalt mixes and binders, Canadian Journal of Civil Engineering 35: 908-917. http://dx.doi.org/10.1139/L08-045

Miró-Recasens, R.; Martínez, A.; Pérez-Jiménez, F.; Bianchetto, H. 2005. Effect of filler on the aging potential of asphalt mixtures, Transportation Research Record: Journal of the Transportation Research Board 1901: $10-17$. http://dx.doi.org/10.3141/1901-02

Molenaar, A. A. A.; Hagos, E. T.; van de Ven, M. F. C. 2010. Effects of aging on the mechanical characteristics of bituminous binders in PAC, Journal of Materials in Civil Engineering ASCE 22(8): 779-787. http://dx.doi. org/10.1061/(ASCE)MT.1943-5533.0000021

Muniandy, R.; Aburkaba, E. E.; Hamid, H. B.; Yunus, R. B. T. 2009. An initial investigation of the use of local industrial wastes and by-products as mineral fillers in stone mastic asphalt pavements, Journal of Engineering and Applied Sciences 4(3): 54-63.

NLT 176 Apparent density of mineral power. 1992. Spanish committee for standardization (CEDEX). $10 \mathrm{p}$.

Páez-Dueñas, A.; Pérez-Jiménez, F.; Miró-Recasens, R. 2009. Evaluation of the cohesion of crumb rubber modified bitumens by means of UCL method, Road Materials and Pavement Design 10(3): 667-676.

Radziszewski, P. 2007. Modified asphalt mixtures resistance to permanent deformations, Journal of Civil Engineering and Management 13(4): 307-315.

Valdés, G.; Pérez-Jiménez, F.; Miró, R.; Martínez, A.; Botella, R. 2011. Experimental study of recycled asphalt mixtures with high percentages of reclaimed asphalt pavement (RAP), Construction and Building Materials 25(3): 1289-1297.

http://dx.doi.org/10.1016/j.conbuildmat.2010.09.016

Vikan, H.; Justnes, H.; Winnefeld, F.; Figi, R. 2007. Correlating cement characteristics with rheology of paste, Cement and Concrete Research 37(11): $1502-1511$.

http://dx.doi.org/10.1016/j.cemconres.2007.08.011

Diana MOVILLA-QUESADA. PhD researcher of the Construction Technology Research Group located at Civil Engineering School of Santander (Spain). She has various studies on pavements and soils materials and she has worked in projects for International companies as ACCIONA Infrastructures and CALCINOR. Also she has written various paper researches about soils and its behaviour adding new materials and bituminous mixtures.

Ángel VEGA-ZAMANILLO. Professor of the School of Civil Engineering of the University of Cantabria (Spain). $\mathrm{He}$ is a lecturer of the subject of Roads and specialist in sub-grades and pavement materials. He is a member of the Transportation Engineering Forum (FIT) in Spain, which promotes the development of congresses and activities related with Transport Engineering, both nationally and internationally.

Miguel Ángel CALZADA-PÉREZ. Professor of the School of Civil Engineering of the University of Cantabria (Spain). $\mathrm{He}$ is a specialist in bituminous mixtures and pavements. He was one of the creators of the porous asphalt mixtures in the 80 's, nowadays globally recognized. In his thesis he developed the Cantabrian test which is internationally normalized and also designed a device called permeometer used to check the porosity in the asphalt mixtures.

Daniel CASTRO-FRESNO. Professor of Construction Engineering and Technical Manager of the Construction Technology Research Group (GITECO in Spanish), from the School of Civil Engineering of the University of Cantabria. He is the author of more than 30 scientific papers and has transferred the results of his investigations to the business sector by 12 patents. His lines of research deal with the development of new construction technologies in roads, as well as with the research of new systems of optimization and collection of renewable energies in roads. 